\title{
Avaliação do alinhamento articular dinâmico dos membros inferiores e a relação com lesões e performance em patinadores
}

http://dx.doi.org/10.11606/1807-5509202000030419

\author{
Mariana Carolina Maciel CABRAL* \\ Emanuelle Francine Detogni SCHMIT* \\ Cláudia Tarragô CANDOTTI*
}

*Universidade Federal do Rio Grande do

Sul, Porto Alegre, RS, Brasil.

\begin{abstract}
Resumo
0 objetivo deste estudo foi analisar o alinhamento articular dinâmico dos membros inferiores de patinadores artísticos sobre rodas e verificar a relação com o histórico de lesões e performance. Foram avaliadas 31 patinadoras $(15,7 \pm 4,8$ anos; $8,2 \pm 4,4$ anos de prática da modalidade), acerca do alinhamento articular dinâmico dos membros inferiores (instrumento MADAAMI-P), do histórico de lesões e da performance (questionário). As análises estatísticas descritivas (média, desvio padrão, frequências) e inferenciais (teste de Shapiro-Wilk, correlação de Pearson/Spearman, teste $t$ dependente/Wilcoxon, $\alpha=0,05$ ) foram realizadas no software SPSS v. 20.0. Os resultados indicam que o início da fase competitiva se dá por volta dos nove anos $(9,1 \pm 3,1$ anos), na frequência de quatro treinos semanais $(4,4 \pm 0,7$ treinos $)$ semana), com ampla quantidade de medalhas obtidas no último ano $(n=231)$. Quanto às lesões em membros inferiores, estas totalizaram 28, e os principais acometimentos envolveram joelho $(n=09)$ e tornozelo $(n=08)$, comumente relacionados à distensão e/ou estiramento $(n=07) .0$ alinhamento articular dinâmico dos membros inferiores foi de bom a excelente (escore mínimo de 53 e máximo de 99\%). As correlações entre o alinhamento articular dinâmico dos membros inferiores com o histórico de lesões e com a performance não foram estatisticamente significativas, tanto quando avaliado o movimento de flexão, como quando o de semiflexão de joelhos, seja em relação ao alinhamento do arco do pé, do joelho ou da pelve. Conclui-se que o alinhamento articular dinâmico dos membros inferiores não é determinante de lesões na patinação nem de baixo desempenho na modalidade.
\end{abstract}

PalavRas-chave: Patinação; Extremidade inferior; Desempenho atlético; Educação Física e treinamento.

\section{Introdução}

A patinação artística é uma modalidade desportiva que combina aspectos característicos do atletismo, da força, da flexibilidade, da resistência e da arte ${ }^{1}$. Pode ser realizada tanto em pista normal quanto no gelo, diferindo primariamente no estilo de patins utilizados $^{2}$, o qual normalmente é composto pela bota, base e rodas ou lâmina. Quando realizada em pista normal, com caráter coreográfico, é denominada patinação artística sobre rodas (PAsr).

Atualmente, os patinadores tem desenvolvido, cada vez mais, movimentos de maior complexidade, dentre os quais estão os saltos, as piruetas e os giros, que acabam por promover sobrecarga nos membros inferiores ${ }^{1}$. Nesses movimentos o peso corporal é distribuído em áreas diferentes dos patins: na parte de trás ou da frente, no lado interno e/ou externo, provocando grande estresse sobre os joelhos e pés. Além disso, todos os movimentos são realizados de forma unipodal e em deslocamento circular, o que torna difícil a manutenção do alinhamento postural. Portanto, estas posiçóes aumentam o estresse das articulações e podem gerar posturas defeituosas, as quais resultam em maior propensão a lesôes ${ }^{3}$.

Dentre as lesões mais comuns na PAsr estáo àquelas relacionadas às questôes músculo esqueléticas e, frequentemente, causadas por esforço repetitivo. 
Os fatores que contribuem para essas lesóes são os patins, o regime de treinos, as questóes ambientais e as convençóes do desporto de alta competição ${ }^{1}$. Além disso, existe uma prevalência de lesôes no membro inferior ${ }^{4}$, a qual pode estar relacionada com a mecânica de propulsão do salto, pois envolve um movimento excessivo de pronação na articulação subtalar ${ }^{5}$.

Diante do exposto, a análise das respostas cinemáticas e cinéticas dos patinadores é fundamental para a compreensão e desenvolvimento das necessidades físicas e técnicas de um patinador. Nesse sentido, conhecer o alinhamento postural dos membros inferiores,

\section{Método}

O presente estudo, com delineamento do tipo ex-pos-facto descritivo correlacional, transversal e retrospectivo ${ }^{6}$, foi aprovado pelo Comitê de Ética em Pesquisa da Universidade Federal do Rio Grande do Sul (CAAE:58157016.0.0000.5347) e realizado, em consonância com as diretrizes da resolução 466/12 do Conselho Nacional de Saúde, nas dependências do Campeonato Panamericano de Patinaçấo Artística no Ginásio Municipal de São Leopoldo, RS.

Para responder ao problema de pesquisa, a amostra foi definida com base em cálculo amostral, utilizando o Al-Therapy Statistics ${ }^{\text {Beta }}$ (https://www. ai-therapy.com/psychology-statistics/sample-sizecalculator), admitindo um teste bicaudal, uma expectativa de correlação mínima $(\mathrm{r}=0,5)$, um poder de $80 \%$ e um nível de significância de 0,05 , sendo necessário um mínimo de 31 indivíduos. Foram incluídos, após esclarecidos os objetivos e procedimentos a serem realizados, e mediante a leitura e assinatura do Termo de Consentimento Livre e Esclarecido, patinadores exclusivamente do sexo feminino, devido ao perfil de atletas da modalidade $^{1}$, praticantes regulares de PAsr com frequência de no mínimo quatro vezes por semana durante o período avaliativo, com idade mínima de 18 e máxima de 35 anos e três anos de experiência ininterrupta na modalidade. Não foram incluídos indivíduos que apresentassem alguma lesão atual ou pregressa que os impedisse de frequentar as aulas regularmente no período de coleta de dados.

A avaliação do alinhamento articular dinâmico dos membros inferiores foi realizada utilizando o instrumento de avaliação MADAAMI-P - Método durante movimentos básicos da PAsr pode contribuir para o aprimoramento técnico, para reabilitaçáo e/ ou prevençáo de lesóes que acometem comumente as articulaçóes que compóem os membros inferiores dos patinadores. Nesse contexto, especula-se que quanto menor o nível de alinhamento articular dinâmico dos membros inferiores, maior é a ocorrência de lesóes e mais baixa é a performance na modalidade. Dessa forma, o objetivo do presente estudo foi analisar o alinhamento articular dinâmico dos membros inferiores de patinadores artísticos sobre rodas e verificar a relação desse alinhamento com o histórico de lesões e performance na modalidade.

de Avaliação Dinâmica do Alinhamento Articular de Membros Inferiores em Paralelo (adaptado de Gontijo et al. ${ }^{7}$ ), o qual consiste em filmagens no plano frontal dos membros inferiores e de uma planilha de pontuação referente à execução do movimento de agachamento no que tange ao alinhamento da pelve, dos joelhos com os pés e a sustentação do arco longitudinal dos pés durante sua execução. A sequência de movimentos avaliada foi: (1) uma repetição de um semi-agachamento com pés paralelos, em apoio bipodal; (2) uma repetiçáo de um agachamento $\left(90^{\circ}\right.$ de flexão de joelhos), com pés paralelos, em apoio bipodal; (3) uma repetição de um semi-agachamento em apoio unipodal direito; e (4) uma repetiçáo de um semi-agachamento em apoio unipodal esquerdo (FIGURA 1).

A aquisição da filmagem desses movimentos foi realizada em um único dia pelo mesmo avaliador capacitado por meio de câmera digital (DSC-W510 - 12.1 megapixels, Sony ${ }^{\oplus}$ ), com o indivíduo posicionado a uma distância padronizada de $1,75 \mathrm{~m}$ do tripé, onde a câmera foi colocada a uma altura de $0,47 \mathrm{~m}$. Para auxiliar na avaliação, foi fixado um fio de prumo alinhado com o centro da lente da câmera e o centro do corpo do indivíduo. E, a fim de identificar as estruturas anatômicas de interesse, foi realizada a palpação e a colocação de marcadores esféricos de isopor nos seguintes processos anatômicos, nos lados direito e esquerdo: espinha ilíaca ânterossuperior, tuberosidade anterior da tíbia, osso navicular e segunda articulação metatarso-falangeana.

A análise dos vídeos e preenchimento da planilha de pontuação do MAADAMI-P foi realizada pelo 
mesmo avaliador que obteve as filmagens. A análise leva em consideração o alinhamento dos membros inferiores de forma geral e segmentar (pelve, joelho e arco plantar), onde a pontuação é mais elevada quanto mais próximo do alinhamento ideal esperado para o movimento o indivíduo estiver (QUADRO 1). Uma vez que não há uma classificação do alinhamento proposta pelo MAADAMI-P, foi adotada uma análise percentual, onde o valor máximo possível de ser obtido no escore equivale a $100 \%$, e, consequentemente, o valor mínimo equivale a $0 \%$. Diante disso, assumiram-se as seguintes categorias de alinhamento articular: pobre < $50 \%$, moderado - entre 51 e $70 \%$, bom - entre 71 e $90 \%$, e excelente $>91 \%$.

A avaliação da ocorrência de lesóes bem como da performance na modalidade, foi realizada a partir do questionário adaptado de CARAzzato, Cabrita e Castropil ${ }^{8}$, o qual visou identificar as principais lesões ocorridas nos membros inferiores e a quantidade de medalhas obtidas no último ano. Esse questionário foi respondido individualmente por cada patinadora, sem qualquer tipo de intervenção do avaliador, sempre após a avaliação do alinhamento articular.

Os dados foram analisados por meio do software SPSS v. 20.0, sendo adotado o nível de significância de 0,05 em todas as análises inferenciais, e seguidas as recomendaçóes de FIELD ${ }^{9}$. Foram realizadas análises descritivas (média, desvio padrão e distribuição de frequências). A fim de verificar a existência de correlação entre a variável independente (alinhamento articular dinâmico dos membros inferiores) e as dependentes (lesóes em membros inferiores e performance na modalidade) foram realizados os testes de correlação de Pearson e Spearman, de acordo com a normalidade dos dados, verificada a priori por meio do teste de Shapiro-Wilk, respeitando a natureza da variável (categórica ou escalar). Foi adotada, para interpretação correlacional, a classificação de GAYA et al. ${ }^{6}$, categorizada em muito baixa $(\mathrm{r}<0,2)$, baixa (entre 0,2 e 0,39), moderada (entre 0,4 e $0,69)$, alta (entre 0,7 e 0,89$)$ e muito alta $(0,9$ a 1). Além disso, de modo a comparar os escores entre os lados direito e esquerdo, após verificada normalidade dos dados, fora aplicado o teste $\mathrm{t}$ dependente ou teste de Wilcoxon.

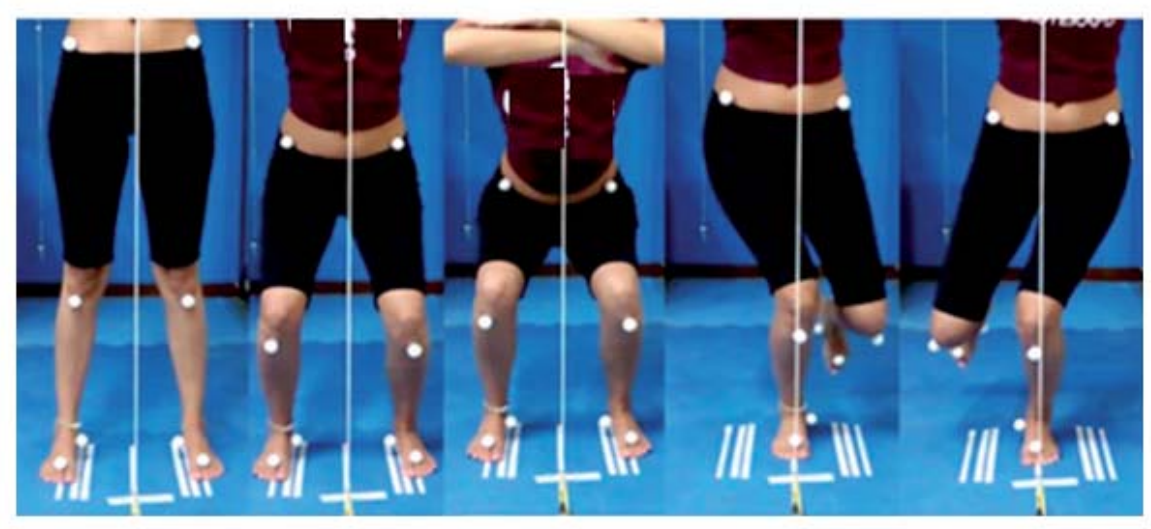

FIGURA 1 - Sequência de movimentos que compõe o MADAAMI-P, partindo da posição em pé. 
QUADRO 1- Escores máximo e mínimo da planilha avaliativa do MADAAMI-P para quantificar o alinhamento articular dinâmico de membros inferiores.

O alinhamento total é composto pela soma do máximo total de cada membro inferior e do mínimo da pelve total?.

\begin{tabular}{lcc}
\hline Movimento/Segmento avaliado & Mínimo & Máximo \\
\hline Alinhamento total & 64 & 164 \\
Total membro inferior direito/esquerdo & 28 & 74 \\
Semi-flexão bipodal & 20 & 52 \\
Flexão de 90 de joelhos & 20 & 52 \\
Semi-flexão unipodal total & 24 & 60 \\
Semi-flexão unipodal direita/esquerda & 12 & 30 \\
Pelve total & 16 & 32 \\
Joelho total & 24 & 60 \\
Joelho direito/esquerdo & 12 & 30 \\
Arco do pé total & 24 & 72 \\
Arco do pé direito/esquerdo & 12 & 36 \\
\hline
\end{tabular}

\section{Resultados}

Foram avaliadas 31 patinadoras com idade média de $15,7 \pm 4,8$ anos e com $8,2 \pm 4,4$ anos de prática da modalidade, cujo início da fase competitiva foi por volta dos nove anos de idade $(9,1 \pm 3,1$ anos). As patinadoras tinham uma frequência de quatro treinos semanais $(4,4 \pm 0,7$ treinos/semana; $10,5 \pm 6,8$ horas/semana) e, no último ano, tinham em média, obtido 7,5 $\pm 7,6$ medalhas cada uma.

No que se referem às lesões nos membros inferiores, no último ano as patinadoras contabilizaram um total de 28 lesóes, o que equivale a uma baixa ocorrência, já que algumas delas chegaram a não se lesionar no período estabelecido. Os principais acometimentos envolveram joelho $(n=09)$ e tornozelo $(n=08)$, seguido de pé e dedos $(\mathrm{n}=05)$, coxa $(\mathrm{n}=04)$ e perna $(\mathrm{n}=02)$, sendo comumente relacionados à distensão e/ou estiramento $(\mathrm{n}=07)$ (TABELA 1$)$.

Quanto ao alinhamento articular dinâmico dos membros inferiores, os escores obtidos na avaliação de cada um dos movimentos de agachamento, bem como das regióes avaliadas (pelve, joelho e arco plantar), foram de bom a excelente (TABELA 2). Cabe destacar ainda, que não foram observadas diferenças entre os membros inferiores no somatório total $(\mathrm{T}=140, \mathrm{p}=0,245)$.

Quanto aos resultados das correlaçóes, considerando o alinhamento total e o alinhamento nas posiçóes de semiflexão uni e bipodal, bem como flexão a $90^{\circ}$, também subdivididas de acordo com as regiōes avaliadas (pelve, joelho e arco plantar), foram não significativas com o histórico de lesóes e a performance na modalidade (TABELA 3). 
TABELA 1 - Distribuição de frequências da ocorrência, local e tipo de lesão no último ano.

\begin{tabular}{|c|c|c|}
\hline Local & Ocorrência (n) & Tipo de lesão (n) \\
\hline Coxa & 04 & $\begin{array}{l}\text { Distensão (03) } \\
\text { Estiramento (01) }\end{array}$ \\
\hline Joelho & 09 & $\begin{array}{l}\text { Desgaste cartilagíneo (02) } \\
\text { Esforço repetitivo (01) } \\
\text { Tendinite (01) } \\
\text { Torção (03) } \\
\text { Síndrome do impacto Jumper Knee (01) } \\
\text { Síndrome femuropatelar (01) }\end{array}$ \\
\hline Perna & 02 & $\begin{array}{l}\text { Tendinite (01) } \\
\text { Distensão (01) }\end{array}$ \\
\hline Tornozelo & 08 & $\begin{array}{l}\text { Calcificação (01) } \\
\text { Cisto sinovial (01) } \\
\text { Distensão (01) } \\
\text { Torçâa (05) }\end{array}$ \\
\hline Pé e dedos & 05 & $\begin{array}{l}\text { Desgaste ósseo (01) } \\
\text { Distensão (01) } \\
\text { Fratura (02) } \\
\text { Tendinite }(01)\end{array}$ \\
\hline
\end{tabular}

Tempo de intern. (dias) = tempo de internação em dias.

*Um participante não respondeu o item filhos *Um participante não respondeu com quem mora 
TABELA 2 - Escores obtidos na avaliação do alinhamento articular dinâmico de membros inferiores das patinadoras.

\section{Categorias de} alinhamento com base no percentual do escore: Pobre $<50 \%$;

Moderado - entre 51 e 70\%;

Bom - entre 71 e $90 \%$; e Excelente $>91 \%$.

\begin{tabular}{lcccc}
\hline Movimento/Segmento avaliado & Média & Desvio padrão & \% do escore & Classificação \\
\hline Alinhamento total & 124,7 & 6,5 & 76 & Bom \\
Total membro inferior direito & 56,9 & 3,7 & 76 & Bom \\
Total membro inferior esquerdo & 58,3 & 5,1 & 79 & Bom \\
Semi-flexão bipodal & 40,1 & 2,8 & 77 & Bom \\
Flexão de 90 de joelhos & 39,1 & 3,1 & 75 & Bom \\
Semi-flexão unipodal total & 44,5 & 3,2 & 74 & Bom \\
Semi-flexão unipodal direita & 22,2 & 1,8 & 74 & Bom \\
Semi-flexão unipodal esquerda & 22,6 & 1,9 & 75 & Bom \\
Pelve total & 20,7 & 3,1 & 65 & Moderado \\
Joelho total & 33,1 & 4,2 & 55 & Moderado \\
Joelho direito & 15,9 & 2,4 & 53 & Moderado \\
Joelho esquerdo & 17,3 & 2,8 & 58 & Moderado \\
Arco do pé total & 70,9 & 2,3 & 98 & 99 \\
Arco do pé direito & 35,5 & 1,2 & 99 & Excelente \\
Arco do pé esquerdo & 35,5 & Excelente
\end{tabular}

TABELA 3 - Correlação entre o alinhamento articular dinâmico demembros inferiores e o histórico de lesões e a performance das patinadoras.

\begin{tabular}{lcccc}
\hline & \multicolumn{2}{c}{$\begin{array}{c}\text { Alinhamento versus } \\
\text { Lesóes }\end{array}$} & \multicolumn{2}{c}{$\begin{array}{c}\text { Alinhamento versus } \\
\text { Performance }\end{array}$} \\
\cline { 2 - 5 } Movimento/Segmento avaliado & \multicolumn{2}{c}{$\mathbf{p}$} & $\mathbf{r}$ & $\mathbf{p}$ \\
\hline Alinhamento total & $-0,193$ & 0,299 & 0,218 & 0,240 \\
Total membro inferior direito & $-0,110$ & 0,556 & $-0,102$ & 0,586 \\
Total membro inferior esquerdo & 0,115 & 0,539 & $-0,201$ & 0,278 \\
Semi-flexão bipodal & $-0,214$ & 0,248 & 0,179 & 0,334 \\
Flexão de 90o de joelhos & 0,054 & 0,775 & $-0,009$ & 0,963 \\
Semi-flexão unipodal total & $-0,168$ & 0,368 & 0,305 & 0,095 \\
Semi-flexão unipodal direita & $-0,170$ & 0,360 & 0,140 & 0,451 \\
Semi-flexão unipodal esquerda & $-0,400$ & 0,832 & 0,178 & 0,337 \\
Pelve total & $-0,279$ & 0,129 & 0,352 & 0,052 \\
Joelho total & $-0,096$ & 0,608 & $-0,078$ & 0,667 \\
Joelho direito & $-0,338$ & 0,063 & 0,045 & 0,809 \\
Joelho esquerdo & 0,107 & 0,566 & $-0,128$ & 0,493 \\
Arco do pé total & 0,188 & 0,312 & 0,080 & 0,669 \\
Arco do pé direito & 0,093 & 0,620 & 0,070 & 0,709 \\
Arco do pé esquerdo & 0,114 & 0,540 & 0,184 & 0,323 \\
\hline
\end{tabular}




\section{Discussão}

A análise do alinhamento articular dinâmico dos membros inferiores demonstrou que as patinadoras apresentam alinhamentos classificados de bom à excelente (TABELA 2), sugerindo que a prática da modalidade, até o momento, não ocasionou prejuízos posturais nessas atletas. Ainda, cabe salientar que não foram encontradas diferenças significativas no que diz respeito à comparaçâo do alinhamento entre os lados direito e esquerdo, resultado esse positivo para a prática da patinaçấo artística, que evidencia a simetria e a ausência de desequilíbrios posturais unilaterais evidentes, mesmo a modalidade enfatizando movimentos complexos com descarga de peso em apenas um membro inferior ${ }^{1}$.

No que tange a caracterização da amostra, o início da fase competitiva se deu por volta dos nove anos de idade, um pouco tardio segundo SMITH ${ }^{10}$ e Lipetz e KRUSE ${ }^{11}$, os quais afirmam que comumente se dá entre a faixa de cinco à oito anos de idade. Ainda, de acordo com SMith $^{10}$ e Dubravcic-Simunjak et al. ${ }^{12}$, os patinadores treinam por duas à quatro horas diárias, contabilizando semanalmente um mínimo de 14 horas, um total em média maior do que o praticado pela amostra do presente estudo.

Segundo Fortin e Roberts 5 , o nível de competitividade e as variadas modalidades da patinação artística fazem com que os atletas tenham que se empenhar o máximo possível nos treinamentos para alcançar os requisitos mínimos necessários para se inscreverem nas competiçóes que ocorrem durante todo o ano, o que, aumenta a vulnerabilidade à ocorrência de lesóes. Whiting e Zernicke ${ }^{13}$ definem lesão como um dano sofrido pelos tecidos do corpo em resposta a um traumatismo físico. No presente estudo, foi observada baixa ocorrência de lesôes nos membros inferiores (TABELA 1), ou seja, um total de 28 lesóes no último ano, em uma amostra composta por 31 patinadoras, indica que algumas das atletas chegaram a nem sequer se lesionar. De acordo com Lipetz e Kruse ${ }^{11}$, 50\% das lesôes que acometem patinadoras são traumáticas e $50 \%$ são acarretadas por algum mecanismo de uso excessivo e/ou sobrecarga. A maioria das lesões que acometeram as patinadoras podem ser caracterizadas como sendo ocasionadas por uso excessivo e/ou sobrecargas (distensão e/ou estiramento), o que corrobora com o observado por Dubravcic-Simunjak et al. ${ }^{12}$. Tais lesões podem estar relacionadas com a frequência e intensidade dos treinos, bem como a possível ausência de medidas preventivas, a exaustão competitiva, a volúpia atlética e, até mesmo, ao psicossomatismo ${ }^{14}$.

Com relação aos pés e dedos, fraturas ocasionadas por stress são comumente observadas ${ }^{1}$, assim como, entorses no tornozelo ${ }^{1,12}$, o que corrobora com o observado no presente estudo. Já, lesóes relacionadas ao joelho, como síndrome patelofemoral e tendinite patelar, são mais comuns em atletas de elite do que amadores ${ }^{1}$, sendo ínfima a frequência de ocorrência encontrada no presente estudo. Chama atenção o fato das atletas apresentarem alinhamento dinâmico articular do joelho moderado e do arco do pé, mais ligado a questôes que envolvem o tornozelo, excelente, mesmo estes segmentos sendo os mais acometidos por lesóes, o que pode auxiliar a explicar a ausência de correlação estatisticamente significativa entre as variáveis alinhamento articular dinâmico e histórico de lesões.

Uma questâo a ser levada em consideração é que a maior parte dos atletas lesionados não interrompe sua fase competitiva para tratamento das lesóes ${ }^{15,16}$, o que contribui para recidiva e ocorrência de novos acometimentos. Tais atletas, tem assim, as mesmas possibilidades que aqueles náo lesionados de conquistar uma medalha, náo sendo a lesão um fator limitante direto da performance. O que parece ser bem justificado mediante os resultados observados no presente estudo, onde as patinadoras obtiveram, em média, aproximadamente sete medalhas cada uma, sugerindo uma amostra com elevada performance.

$\mathrm{O}$ fato das patinadoras terem apresentado um alinhamento articular de moderado a excelente, baixa ocorrência de lesóes e elevada performance gerou correlaçóes, em sua maioria, inversas entre alinhamento e lesōes, e diretas, entre alinhamento e performance, contudo sem significância estatística (TABELA 3). Esse resultado inviabiliza a confirmação da hipótese do presente estudo, onde especulava-se que quanto menor o nível de alinhamento articular dinâmico dos membros inferiores, maior seria a ocorrência de lesóes e mais baixa a performance na modalidade.

Diante do exposto, ressalta-se a importância da atuação de uma equipe multidisciplinar (médicos, fisioterapeutas, educadores físicos e psicólogos) no aconselhamento, orientaçáo e monitoramento da formação de jovens patinadores ${ }^{12}$. Da mesma forma, é importante capacitar e informar aos treinadores e pais sobre a susceptibilidade dos atletas jovens ao acometimento de lesóes. Uma 
abordagem multidisciplinar deve investir tanto nos precipitadores externos de lesóes como nos fatores intrínsecos (crescimento, desequilíbrios músculotendíneos, flexibilidade) ${ }^{12}$. Um bom alinhamento postural, alongamento adequado e programas de reforço ${ }^{17}$, especialmente no período de desenvolvimento assíncrono de tecido ósseo e muscular, podem prevenir e reduzir as síndromes de uso excessivo e sobrecarga ${ }^{12}$.
De forma a sumarizar os achados do presente estudo, pode-se afirmar que as atletas apresentaram alinhamento articular dinâmico dos membros inferiores de moderado a excelente, baixa ocorrência de lesóes e elevada performance. Dessa forma, conclui-se que o alinhamento articular dinâmico dos membros inferiores não foi um fator determinante de lesões ou de baixo desempenho das patinadoras.

\section{Abstract \\ Evaluation of dynamic joint alignment of lower limbs and the relationship with lesions and performance in skaters}

The objective of this study was to analyze the dynamic joint alignment of the lower limbs of artistic skaters on wheels and to verify the relation with the injuries history and the performance. A total of 31 skaters $(15.7 \pm 4.8$ years, $8.2 \pm 4.4$ years of practice) were evaluated, regarding the dynamic joint alignment of the lower limbs (MADAAMI-P instrument), and the injuries history and the performance (questionnaire). The descriptive statistical analyzes (mean, standard deviation, frequencies) and inferential (Shapiro-Wilk test, Pearson/Spearman correlation, $t$-dependent test/Wilcoxon, $\alpha=0.05$ ) were performed in SPSS v. 20.0. The results indicate that the beginning of the competitive phase occurs around nine years $(9.1 \pm 3.1$ years), in the frequency of four weekly training sessions ( $4.4 \pm 0.7$ trainings/week), with large quantity of medals obtained in the last year $(n=231)$. As for inferior members injuries, the main injuries involved knee $(n=09)$ and ankle $(n=08)$, being commonly related to distension and/or stretching $(n=07)$. The dynamic joint alignment of the lower limbs was good to excellent (minimum score 53 and maximum 99\%). The correlations between the dynamic joint alignment of the lower limbs with the injuries history and performance were not statistically significant, as well as the flexion movement is evaluated, as when the knee semi-flexion is evaluated, either in relation to the alignment of the foot arch, knee or pelvis. It is concluded that the lower limbs dynamic joint alignment is not a determinant of skating injuries nor of low performance in the modality.

KEYWORDS: Skating, lower extremity; Athletic performance; Physical education and training.

\section{Referências}

1. Porter EB, Young CC, Niedfeldt MW, Gottschlich LM. Sport-specific injuries and medical problems of figure skaters. WMJ. 2007;106(6):330-4.

2. Duarte O. História dos esportes. 4a. ed. São Paulo: Senac, 2003.

3. Magee DJ. Avaliação Músculoesquelética. 5a. ed. São Paulo: Manole, 2010.

4. Blewitt C, Chockalingam N. An investigation into the incidence of injury in the competitive adult ice skating population: a pilot study. Serb J Sports Sci. 2011;5(4):171-4.

5. Fortin J, Roberts D. Competitive figure skaters injuries. Pain Physician. 2003;6(3):313-8.

6. Gaya A, Garlipp DC, Silva MF, Moreira RB. Ciências do movimento humano: introdução à metodologia da pesquisa. Porto Alegre: Artmed, 2008.

7. Gontijo KNS, Candotti CT, Feijó GS, Ribeiro LP, Loss JF. Dynamic evaluation method of the lower limbs joint alignament (MADAAMI) for dancers during the plié. Rev Bras Ciênc Esporte. 2017;39(2):148-59.

8. Carazzato JG, Cabrita H, Castropil W. Repercussão no aparelho locomotor da prática do judô de alto nível: estudo epidemiológico. Rev Bras Ortop. 1996;31(12):957-68. 
9. Field A. Discovering statistics using SPSS: introducing statistical method. 3a. ed. SAGE Publications Ltd: London, 2009. 10. Smith AD. The young skater. Clin J Sport Med. 2000;19(4):741-55.

11. Lipetz J, Kruse RJ. Injuries and special concerns of female figure skaters. Clin J Sport Med. 2000;19(2):369-80.

12. Dubravcic-Simunjak S, Pecina M, Kuipers H, Moran J, Haspl M. The incidence of injuries in elite junior figure skaters. Am J Sports Med. 2003;31(4):511-7.

13. Whiting WC, Zernicke RF. Biomecânica funcional e das lesões musculoesqueléticas. Rio de Janeiro: Guanabara Koogan, 2009.

14. Gantus MC, Assumpção JDA. Epidemiologia das lesóes do sistema locomotor em atletas de basquetebol. Acta Fisiátr. 2002;9(2):77-84.

15. Hoffmann IS, Toigo AM. Prevalência de lesóes musculotendíneas em atletas amadores de patinação artística federados no estado do Rio Grande do Sul. Rev Mackenzie Educ Fís Esporte. 2015;14(1):219-33.

16. Blewitt C, Chockalingam N. An investigation into the incidence of injury in the competitive adult ice skating population: a pilot study. Serb J Sports Sci. 2011;5(4):171-4.

17. Mohney GTMA, Miller MG, Hanson N. Strengthening the Figure Skater: considerations for injury prevention and performance. Strenght Cond J. 2017;39(3):58-65.

\begin{tabular}{r|l} 
ENDEREÇO & \\
Emanuelle Francine Detogni Schmit & Submetido: 10/05/2017 \\
$\begin{array}{r}\text { R. Prof. Freitas Cabral, 272/ 1006 - Jardim Botânico } \\
\text { 90690-130 - Porto Alegre - RS - Brasil }\end{array}$ & $\begin{array}{r}\text { Revisado: 09/ 10/2017 } \\
\text { E-mail: manu_schmit@hotmail.com, } \\
\text { manu.fran.schmit@gmail.com }\end{array}$ \\
& \\
&
\end{tabular}

